\title{
Pink ribbons for breast cancer awareness - a perspective
}

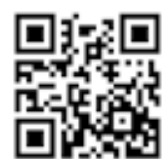

The pink ribbon has become synonymous with breast cancer awareness. Where did the pink ribbon originate? What does breast cancer awareness mean, and can it be used to improve the health of the majority of women in South Africa?

The first ribbon to be linked to a cause was yellow. In 1979, Penney Lainegen, the wife of an Iranian hostage, tied a yellow ribbon round a tree to make people aware of the plight of the hostages. Eleven years later, in 1991, a group of artists came together to design a symbol that would remind the world of the plight of AIDS victims. They designed the red ribbon. Red was chosen as a colour of passion: anger and love. The designers believed that it was important to remain anonymous as individuals and to keep the copyright free so that no organisation or individual could profit from the symbol, and that the red ribbon should be used as a consciousness-raising symbol and not as a commercial tool. ${ }^{[1]}$

In 1990, the Susan G Kommen Foundation (one of the largest breast cancer organisations in the USA) gave out pink visors to participants in their events. At about the same time Susan Haley, an individual working at grassroots level, was making peach-coloured ribbons attached to a card on which she wrote 'The National Cancer Institute's annual budget is 1.8 billion US dollars, and only 5 percent goes to cancer prevention. Help us wake up our legislators and America by wearing this ribbon.

There are two origins of the pink ribbon. The first is that in 1992, Alexandra Peney, editor of Self magazine, was trying to market an edition highlighting breast cancer awareness. She liaised with Evelyn Lauder, vice-president of Estée Lauder, and together they agreed to attach a pink ribbon to all cosmetic products. The second is that the Susan G Kommen Foundation approached Susan Haley to suggest that they work in collaboration with Haley's peach ribbon campaign. When Haley refused, the Foundation adopted the pink ribbon as their symbol. ${ }^{[2]}$

Cause-related marketing is the term used to describe a not-forprofit organisation benefiting from a for-profit company's marketing. The presence of a symbol on a product vouches for the fact that some money will be donated to a cause. The pink ribbon is an example par excellence. Breast cancer is a perfect disease for companies to use because it is blameless in that the main risk factors are being female, growing older and having a positive family history, none of which can be modified by the individual with the cancer. For companies it is a safe cause to link with and, through the cause, to link with women and their impressive purchasing power. It is also an inexpensive form of advertising (hence the term marketing).

All too often, however, only a minute proportion of the money raised ends up going to the cause. For example, in 2002 American Express agreed to donate one cent every time their card was used in October. In reality, a card had to be used one hundred times during the 30 -day period to donate $\$ 1 !^{[3]}$ Another flaw is that the amount donated is usually capped, so that, for example, New Balance has agreed to donate money to the Susan G Kommen Foundation but will cease to donate further once the agreed capped amount has been raised. Also, New Balance donate money from sales of their caps, T-shirts and socks, but not from sales of their pink trainers, which are 'just for awareness. ${ }^{[2]}$

Should the source of the income matter? The presence of pink ribbons on Kentucky Fried Chicken, sweets and fattening products is surely counterintuitive if, for breast cancer survivors, reducing their body mass index is an important factor in decreasing their risk of cancer recurrence.

It is impossible to estimate how much the pink ribbon is worth. It bears noting, however, that the Susan G Kommen Foundation alone raised over $\$ 420$ million in $2012 .{ }^{[4]}$ The vast majority of the funds raised from the pink ribbon campaigns go to 'breast cancer awareness. What does breast cancer awareness mean, and what should we be doing in southern Africa? The Wikipedia definition (interestingly, the only definition I could find) is 'an effort to raise awareness and reduce the stigma of breast cancer through education on symptoms and treatment. ... will lead to earlier detection of breast cancer, which is associated with higher long-term survival rates, and that money raised for breast cancer will produce a reliable, permanent cure. ${ }^{[5]}$

Women in low-income countries are all too often diagnosed late in the course of disease with advanced breast cancer and frequently cannot access the standard of care needed for treatment. There are many similar problems facing women in South Africa, although it is classified as a middle-income country. These are featured in this month's CME. The stigma attached to the diagnosis, cost involved in medical treatment, complex referral pathways and inefficiencies in the system are just a few of the challenges. It does not help

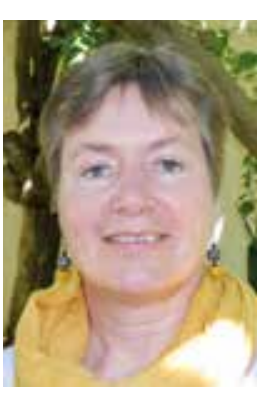
that breast cancer awareness campaigns are largely confined to middle-class suburbs and tailored to the needs of more affluent citizens.

We must know where South Africa's 'pink rand' is going, and whether or not it could be spent more appropriately.

\section{Jenny Edge}

Netcare Christiaan Barnard Memorial Hospital,

Cape Town, South Africa

jennyedge1234@me.com

\footnotetext{
1. https://www.visualaids.org/projects/detail/the-red-ribbon-project (accessed 6 April 2014) 2. http://thinkbeforeyoupink.org (accessed 6 April 2014)

3. King S. Pink Ribbons, Inc.: Breast Cancer and the Politics of Philanthropy. Minneapolis: University . King S. Pink Ribbons, Inc:
of Minnesota Press, 2008.

of Minnesota Press, 2008.
4. http://ww5.komen.org/AboutUs/FinancialInformation.html (accessed 6 April 2014).

5. http://en.wikipedia.org/wiki/Breast_cancer_awareness (accessed 6 April 2014).
}

S Afr Med J 2014;104(5):321. DOI:10.7196/SAMJ.8300 